\title{
Original article \\ Effects of a multimodal exercise program on the functional capacity of Parkinson's disease patients considering disease severity and gender
}

\author{
Diego Orcioli-Silva \\ Fabio Augusto Barbieri \\ Lucas Simieli \\ São Paulo State University, Brazil \\ Natália Madalena Rinaldi \\ University of São Paulo, Brazil \\ Rodrigo Vitório \\ Lilian Teresa Bucken Gobbi \\ São Paulo State University, Brazil
}

\begin{abstract}
The purpose of this study was to investigate the effects of a multimodal exercise program (MEP) on the functional capacity of patients with Parkinson's disease (PD) according to disease severity and gender. Fourteen patients with PD participated in the study and were distributed into groups according to 1) stage of disease and 2) gender. Functional capacity was evaluated before and after 6 months of intervention. The overall PD patient group improved their coordination and strength. Men and women improved in strength performance after exercise. Men also improved on coordination. For severity of disease, the unilateral group improved in strength, while the bilateral group improved in strength, balance, coordination and the UPDRS-functional score. In conclusion, a MEP is efficient in improving components of functional capacity in patients with PD, especially in strength. Gender may be considered in the exercise program. Individuals in the bilateral disease group appeared to benefit more from exercise.
\end{abstract}

Keywords: multimodal exercise program, functional capacity, Parkinson's disease

Resumo - "Efeitos de um programa de exercícios multimodal na capacidade funcional de pacientes com doença de Parkinson considerando a gravidade da doença e sexo". O objetivo deste estudo foi investigar o efeito de um programa de exercício multimodal (PEM) na capacidade funcional de pacientes com doença de Parkinson (DP), de acordo com a severidade da doença e gênero. Catorze pacientes com DP participaram do estudo, distribuídos em dois grupos: 1) severidade da doença, 2) gênero. A capacidade funcional foi avaliada antes e após 6 meses de intervenção. Em geral, os pacientes melhoraram a coordenação e força. Homens e mulheres melhoraram o desempenho da força após o exercício. Os homens também melhoraram a coordenação. Para a severidade da doença, o grupo unilateral melhorou a força, enquanto o grupo bilateral melhorou força, equilíbrio, coordenação e UPDRS funcional. Portanto, o PEM é eficiente na melhoria dos componentes da capacidade funcional de pacientes com DP, especialmente a força. O gênero deve ser considerado no programa de exercício. Pacientes no estágio bilateral parecem ter mais benefícios do exercício.

Palavras-chave: programa de exercício multimodal, capacidade funcional, doença de Parkinson

Resumen - "Efectos de un programa de ejercicio multimodal en la capacidad funcional de los pacientes con enfermedad de Parkinson teniendo en cuenta la gravedad de la enfermedad y el sexo". Esto estudio investigó el efecto de un programa de ejercicio multimodal (PEM) en la capacidad funcional de pacientes con enfermedad de Parkinson (EP), considerando la severidad de la enfermedad y el género. Catorce pacientes con EP participaron del estudio, distribuidos en grupos: 1) severidad de la enfermedad, 2) género. La capacidad funcional fue avaluada antes y después de 6-meses de intervención. En general, los pacientes mejoraron coordinación y fuerza. Hombres y mujeres mejoraron el desempeño de la fuerza después del ejercicio. Todavía, los hombres también mejoraron coordinación. Considerando la gravedad de la enfermedad, el grupo unilateral mejoró fuerza y el grupo bilateral mejoró fuerza, equilibrio, coordinación y la UPDRS-funcional. Así, el PEM fue eficaz en mejorar los componentes de la capacidad funcional de pacientes con EP, especialmente la fuerza. El género debe ser considerado en el programa de ejercicios. Individuos con enfermedad bilateral parecen beneficiarse más de los ejercicios.

Palabras clave: programa de ejercicio multimodal, capacidad funcional, enfermedad de Parkinson 


\section{Introduction}

Parkinson's disease (PD) is a neurodegenerative disease that affects $3.3 \%$ of the Brazilian population (Barbosa et al., 2006). PD causes loss of mobility and the independence to perform daily life activities (Rubinstein, Giladi, \& Hausdorff, 2002). It includes motor symptoms, such as hypokinesia, akinesia, tremor, rigidity and postural instability (Morris, Huxham, McGinley, Dodd, \& Iansek, 2001). In addition to pharmacological treatments that reduce motor and non-motor symptoms in PD (Jankovic \& Stacy, 2007), exercise programs can be considered an efficient strategy to improve functionality, balance, gait and quality of life (Goodwin, Richards, Taylor, Taylor, \& Campbell, 2008). Recent evidence has shown positive changes after an exercise program not only in balance and mobility (Gobbi et al., 2009; Hackney \& Earhart, 2010) but also in motor symptoms (Sage \& Almeida, 2009; Sage \& Almeida, 2010) in patients with PD. In addition, physical activity is an important factor that can improve functional capacity (Cyarto, Brown, Marshall, \& Trost, 2008). However, little is known about the effects of a multimodal exercise program on functional capacity in $\mathrm{PD}$, which is required to successfully perform a greater level of daily activities (Rantanen et al., 1999). Moreover, physical activity programs for patients with $\mathrm{PD}$ are individualized and do not consider gender, age, severity of disease, clinical aspects, or other factors.

Questions remain regarding the optimal content of exercise programs (e.g., intensity, dosing, and component exercises) at different stages of the disease (Goodwin et al., 2008). Disease severity is one of the main factors affecting patients with PD; individuals with advanced PD have low levels of functional capacity (Barbieri et al., 2012). It is important to establish which elements constitute an optimal exercise program for individuals with PD, such as the dosage, the specific components of the exercise program, and the targeted disease stage for treatment (Goodwin et al., 2008). However, there is some evidence in the literature regarding the benefits of physical activity based on the severity of $\mathrm{PD}$, specifically regarding functional capacity.

Motor phenomenology, progression, drug responses and complications are gender-related in PD (Scott, Borgman, Engler, Johnels, \& Aquilonius, 2000; Shulman \& Bhat, 2006; Haaxma et al., 2007). The prevalence of PD and the onset of motor symptoms are greater in men than in women; data on disease incidence suggest that men have at least a two-fold increased risk of PD at all ages (Baldereschi et al., 2000; Van Den Eeden, et al., 2003; Pavon, Whitson, \& Okun, 2010). A variety of gender differences have been found in response to the treatment of PD. For example, women have greater levodopa bioavailability than men after levodopa is metabolized. Moreover, gender influences the response to PD, suggesting that the nature of the disease and the response to treatment may be gender-dependent (CantutiCastelvetri, et al., 2007). However, the influence of physical activity and gender on patients with PD is unknown. Due to differences in the metabolic and muscular systems, as well as in the habits and effects of PD, it is possible that the outcomes of a physical activity program on functional capacity would be different for men and women.
The aim of this study was to investigate the effects of a multimodal exercise program on the functional capacity of patients with PD based on disease severity (unilateral and bilateral groups) and gender (male and female patients with PD). We addressed the following questions: Is functional capacity improved following a multimodal exercise program? Are the effects of a multimodal exercise program on functional capacity related to disease severity and gender? Our general hypothesis was that the components of functional capacity would improve following the exercise program. We expected the components of functional capacity to improve for both the disease severity and gender groups. Specifically, unilateral PD would improve more than bilateral PD due to differences in disease symptoms and functional capacity (Goodwin et al., 2008; Barbieri et al., 2012). For gender, we expected women to show more benefits than men after the exercise program because women benefit more from levodopa treatment (Cantuti-Castelvetri, et al., 2007).

\section{Methods}

\section{Participants and procedures}

All procedures described were approved by the Research Ethics Committee of the São Paulo State University at Rio Claro. Patients were screened and signed a consent form. They were evaluated by an expert physiatrist. The criteria for participation included men and women who had been clinically examined by a physician, had a confirmed diagnosis of PD, scored between I and III on the Hoehn \& Yard Stages of PD, took PD drugs regularly, and were able to walk independently.

The study population consisted of 14 patients (age $67.79 \pm 7.99$ years; age at disease onset $-64.00 \pm 9.40$ years; height $-1.60 \pm 0.06 \mathrm{~m}$; weight $-71.15 \pm 15.03 \mathrm{~kg}$ ) with idiopathic PD who participated in a multidisciplinary project in PD conducted at São Paulo State University at Rio Claro (UNESP-RC). Participants were interviewed and evaluated from February 2006 to December 2008. Three groups, one group per year, participated in the multimodal exercise program. Five patients participated in the exercise program in 2006, five patients participated in 2007, and four patients participated in 2008. Seven men and 7 women who were classified according to PD severity for unilateral disease (stage $1 ; 8$ subjects) and bilateral disease (stages 2 to $3 ; 6$ subjects) participated in the study. All participants performed the same multimodal exercise program. They performed the activities together, independent of gender or PD severity. Participants were matched for gender, disease severity as measured by the Unified Parkinson's Disease Rating Scale (UPDRS), age and age at disease onset.

\section{Multimodal exercise program}

The main aim of the exercise program was to provide training in the components of functional capacity, specifically in strength, coordination and balance. Rhythmic activities were designed to train motor coordination. Gymnastics and strength training were designed to improve strength, specifically in the 
Table 1. Activities for each functional capacity component and the overload sequence.

\begin{tabular}{lll}
\hline Phases & Activities & $\begin{array}{c}\text { Functional } \\
\text { Capacities }\end{array}$ \\
\hline $\mathbf{1}$ & Specific activities for coordination & Coordination \\
& Activities with body's own weight & Strength \\
& Exercises to stimulate the vestibular system & Balance \\
\hline $\mathbf{2}$ & Added trunk movements & Coordination \\
& Added materials with low overload (stick, hoop, rope, etc) & Strength \\
& Exercises to stimulate both the vestibular and visual systems & Balance \\
\hline $\mathbf{3}$ & Added head movements & Coordination \\
& Added material with greater overload (dumbbells, ankle weights, medicine-ball and & Strength \\
& rubber band) & Balance \\
\hline $\mathbf{4}$ & Exercises to stimulate both the visual and somatosensory systems & Coordination \\
& Activities more complex for arms, legs, trunk and head & Strength \\
& Increase of overload & Balance \\
\hline $\mathbf{5}$ & Activities to stimulate vestibular, visual, and somatosensory systems & Coordination \\
& Activities for arms and legs with and without displacement & Strength \\
& Activities in the strength training room with increase overload & Balance \\
\hline $\mathbf{6}$ & Dynamic and static exercises with visual cues & Coordination \\
& Added trunk movements and used materials (hoop, ball, rope) & Strength \\
& Increase overload and volume & Balance \\
\hline
\end{tabular}

large muscle groups. Leisure activities were included to improve balance. Training in aerobic endurance was included with the other functional capacity components and flexibility being addressed by stretching.

The exercise program was performed in 72 sessions over 6 months. Three sessions were performed per week; each session lasted 60 minutes. The session had three parts: the warm-up and stretching (10 minutes), the main section (40 minutes), and the cool-down and final stretching (10 minutes). The exercise program was distributed over six phases. Each phase consisted of 12 sessions. At the end of each phase, there was a gradual increase in load (Table 1). Sessions kept the same schedule (8:30 am to 9:30 am). Patients took Parkinson's disease drugs one hour prior to the start of the session. Therefore, medications were controlled for each patient every month to control for the effects on the exercise program.

\section{Evaluations}

Patients underwent a health screening, clinical evaluation and functional capacity evaluation before and after the exercise program. Both sessions were held between 8:00 and 11:00 a.m. due to patient medication schedules. All participants were evaluated during the "on" state of medication.

During the clinical evaluation, information from subjects was obtained regarding the following general and anthropometrical data: gender, age, age at disease onset, weight and height. On the first day, a psychiatric physician evaluated the signs and symptoms of Parkinson's using the UPDRS to assess mental status, activities in daily living and motor examination; the mental status of patients was assessed with the Mini-Mental State Examination (MMSE) and PD severity was assessed with the modified Hoehn and Yahr Scaling for PD.

For the functional capacity evaluation, physical capacity components were evaluated over two days using tests proposed by the American Alliance for Health, Physical Education, Recreation and Dance (AAHPERD) (Osness et al., 1990) and by the Berg Balance Scale (Scalzo et al., 2009). During the second testing session, each participant performed the balance, flexibility, coordination, strength and agility tests. Aerobic resistance was evaluated on the third day. More detail on the evaluation can be found in Barbieri et al. (2012).

\section{Statistical analyses}

SPSS for Windows $15.0^{\circledR}$ was used for the statistical analysis of data ( $p<0.05$ was considered significant). The Shapiro-Wilk test was used to test data normality. First, we analyzed the overall effects of the exercise program on the components of functional capacity using Student's $t$-test. Then, we compared the groups before the exercise program using two Student's $t$-tests, one for gender and another for disease severity. Finally, to analyze the exercise program effects according to disease severity and gender, two MANOVAs were performed: one for clinical variables and one for the components of functional capacity, with gender (men and women), disease severity (unilateral and bilateral disease) and the exercise program (before and after exercise program) as independent variables with repeated measures of the last factor. 


\section{Results}

The overall PD patient group (Table 2) improved on some components of functional capacity (coordination and strength) after the exercise program. MANOVA indicated that PD patients significantly improved their coordination and strength. MANOVA also indicated similar scores on the clinical variables before and after the exercise program.

Table 2. Mean, standard deviation (range for Hoehn and Yahr), and pvalues for the clinical variables and components of functional capacity collapsed across groups before and after exercise program.

\begin{tabular}{|c|c|c|c|}
\hline & $\begin{array}{c}\text { Before } \\
\text { Exercise } \\
\text { Program }\end{array}$ & $\begin{array}{c}\text { After } \\
\text { Exercise } \\
\text { Program }\end{array}$ & $p$ \\
\hline \multicolumn{4}{|l|}{ Clinical Variables } \\
\hline Hoehn and Yahr & $1.42(1-2)$ & $1.64(1-3)$ & 0.09 \\
\hline $\begin{array}{l}\text { UPDRS - Mentation } \\
\text { (points) }\end{array}$ & $3.79 \pm 2.75$ & $3.79 \pm 2.22$ & 1.00 \\
\hline $\begin{array}{l}\text { UPDRS - Functional } \\
\text { (points) }\end{array}$ & $12.50 \pm 8.31$ & $11.79 \pm 8.04$ & 0.12 \\
\hline $\begin{array}{l}\text { UPDRS - Motor } \\
\text { (points) }\end{array}$ & $22.93 \pm 14.83$ & $23.29 \pm 16.24$ & 0.77 \\
\hline UPDRS - Total (points) & $39.21 \pm 23.76$ & $38.86 \pm 24.23$ & 0.77 \\
\hline $\begin{array}{l}\text { MINIMENTAL } \\
\text { (points) }\end{array}$ & $26.75 \pm 3.45$ & $26.11 \pm 4.44$ & 0.30 \\
\hline \multicolumn{4}{|l|}{$\begin{array}{l}\text { Functional Capacity } \\
\text { Components }\end{array}$} \\
\hline Balance (points) & $52.86 \pm 4.15$ & $53.57 \pm 2.71$ & 0.19 \\
\hline Flexibility (cm) & $47.56 \pm 12.10$ & $50.14 \pm 10.53$ & 0.17 \\
\hline Coordination (s) & $18.50 \pm 7.58$ & $15.89 \pm 6.84$ & $0.005^{*}$ \\
\hline Agility (s) & $28.82 \pm 12.37$ & $30.74 \pm 11.54$ & 0.64 \\
\hline Strength (rep) & $19.79 \pm 6.57$ & $23.50 \pm 5.33$ & $0.001 *$ \\
\hline $\begin{array}{l}\text { Aerobic Resistance } \\
\text { (min) }\end{array}$ & $10.08 \pm 2.45$ & $10.13 \pm 2.90$ & 0.83 \\
\hline
\end{tabular}

Clinical variables and scores on components of functional capacity before the exercise program were similar between men and women (Tables 3 and 4). A multivariate analysis indicated improved strength performance for men and women. Men also improved on coordination after the exercise program. For clinical variables, there were no significant differences in the scores before and after the exercise program between genders.

The unilateral and bilateral groups showed differences in PD severity (Tables 3 and 4 ) before the exercise program as measured by the UPDRS-functional $(p<0.01)$, UPDRS-motor $(p<0.003)$, UPDRS-total $(p<0.004)$, balance $(p<0.003)$, coordination $(p<0.001)$, strength $(p<0.02)$ and aerobic resistance $(p<0.01)$. A MANOVA indicated improved strength performance for the unilateral and bilateral groups. In addition, the patients with bilateral disease improved balance and coordination after the exercise program. The bilateral disease group improved in the UPDRS-functional score for the clinical variables.

\section{Discussion}

The aim of this study was to investigate the effects of a multimodal exercise program on the functional capacity of patients with PD considering disease severity and gender. In general, we found that the multimodal exercise program improved some components of functional capacities (coordination and strength) and maintained the clinical characteristics. Interestingly, strength improved independent of gender and disease severity but in contrast to our hypothesis. Specifically, men improved coordination and the bilateral disease group showed more benefits after the exercise program. We expected that women and the unilateral group would show more benefits from the exercise program.

The multimodal exercise program was efficient in improving the coordination and strength of patients with PD. Despite the limitation of not including a control group to directly measure the effectiveness of the intervention, the results suggest that the multimodal exercise program could improve some components

Table 3. Mean, standard deviation, and p-values for the clinical variables according to gender and disease severity, before (BF) and after (AF) exercise program.

\begin{tabular}{|c|c|c|c|c|c|c|c|c|c|}
\hline & & Men & $p$ & Women & $p$ & Unilateral & $p$ & Bilateral & $p$ \\
\hline Hoehn and Yahr & $\begin{array}{l}\mathrm{BF} \\
\mathrm{AF}\end{array}$ & $\begin{array}{l}1.43 \pm 0.20 \\
1.71 \pm 0.33\end{array}$ & 0.11 & $\begin{array}{l}1.43 \pm 0.20 \\
1.57 \pm 0.33\end{array}$ & 0.40 & ------ & ------ & ------ & ------ \\
\hline $\begin{array}{l}\text { UPDRS - Menta- } \\
\text { tion (pts) }\end{array}$ & $\begin{array}{l}\mathrm{BF} \\
\mathrm{AF}\end{array}$ & $\begin{array}{l}4.71 \pm 1.01 \\
4.43 \pm 0.83\end{array}$ & 0.40 & $\begin{array}{l}2.86 \pm 1.01 \\
3.14 \pm 0.83\end{array}$ & 0.40 & $\begin{array}{l}3.12 \pm 0.97 \\
3.12 \pm 0.76\end{array}$ & 1.00 & $\begin{array}{l}4.66 \pm 1.12 \\
4.66 \pm 0.88\end{array}$ & 1.00 \\
\hline $\begin{array}{l}\text { UPDRS - Func- } \\
\text { tional (pts) }\end{array}$ & $\begin{array}{l}\mathrm{BF} \\
\mathrm{AF}\end{array}$ & $\begin{array}{l}15.71 \pm 2.99 \\
15.00 \pm 2.88\end{array}$ & 0.87 & $\begin{array}{l}9.29 \pm 2.99 \\
8.57 \pm 2.88\end{array}$ & 0.58 & $\begin{array}{l}8.00 \pm 2.33 \\
7.87 \pm 2.40\end{array}$ & 0.81 & $\begin{array}{l}18.50 \pm 2.69 \\
17.00 \pm 2.78\end{array}$ & $0.024 *$ \\
\hline $\begin{array}{l}\text { UPDRS - Motor } \\
(\mathrm{pts})\end{array}$ & $\begin{array}{l}\mathrm{BF} \\
\mathrm{AF}\end{array}$ & $\begin{array}{l}29.00 \pm 5.28 \\
28.71 \pm 5.99\end{array}$ & 0.33 & $\begin{array}{l}16.86 \pm 5.28 \\
17.86 \pm 5.99\end{array}$ & 0.74 & $\begin{array}{l}13.85 \pm 3.72 \\
12.13 \pm 3.39\end{array}$ & 0.22 & $\begin{array}{l}35.00 \pm 4.30 \\
38.17 \pm 3.92\end{array}$ & 0.07 \\
\hline $\begin{array}{l}\text { UPDRS - Total } \\
\text { (pts) }\end{array}$ & $\begin{array}{l}\mathrm{BF} \\
\mathrm{AF}\end{array}$ & $\begin{array}{l}49.43 \pm 8.36 \\
48.14 \pm 8.74\end{array}$ & 0.46 & $\begin{array}{c}29.0 \pm 8.36 \\
29.57 \pm 8.74\end{array}$ & 0.74 & $\begin{array}{l}25.00 \pm 6.09 \\
23.12 \pm 5.60\end{array}$ & 0.23 & $\begin{array}{l}58.17 \pm 7.04 \\
59.83 \pm 6.46\end{array}$ & 0.35 \\
\hline MMSE (pts) & $\begin{array}{l}\mathrm{BF} \\
\mathrm{AF}\end{array}$ & $\begin{array}{l}27.36 \pm 1.33 \\
25.86 \pm 1.74\end{array}$ & 0.11 & $\begin{array}{l}26.14 \pm 1.33 \\
26.36 \pm 1.74\end{array}$ & 0.81 & $\begin{array}{l}27.81 \pm 1.18 \\
27.56 \pm 1.50\end{array}$ & 0.77 & $\begin{array}{l}25.33 \pm 1.36 \\
24.17 \pm 1.73\end{array}$ & 0.26 \\
\hline
\end{tabular}

* $p<0.05$; Unified Parkinson's Disease Rating Scale (UPDRS); Mini-Mental State Examination (MMSE) 
Table 4. Mean, standard deviation, and p-values for the components of functional capacity according to gender and disease severity, before (BF) and after (AF) exercise program.

\begin{tabular}{lccccccccc}
\hline & & Men & $\boldsymbol{p}$ & Women & $\boldsymbol{p}$ & Unilateral & $\boldsymbol{p}$ & Bilateral & $\boldsymbol{p}$ \\
\hline Balance (pts) & BF & $52.71 \pm 3.54$ & 0.70 & $53.00 \pm 4.96$ & 0.15 & $55.37 \pm 0.74$ & 0.67 & $49.50 \pm 4.50$ & $0.01^{*}$ \\
& AF & $53.00 \pm 2.58$ & & $54.14 \pm 2.91$ & & $55.12 \pm 1.12$ & & $51.50 \pm 2.88$ & \\
Flexibility (cm) & BF & $43.12 \pm 14.28$ & 0.28 & $51.98 \pm 8.21$ & 0.36 & $50.61 \pm 13.52$ & 0.11 & $43.48 \pm 9.46$ & 0.72 \\
& AF & $45.92 \pm 12.01$ & & $54.35 \pm 7.37$ & & $54.43 \pm 9.29$ & & $44.41 \pm 9.92$ & \\
Coordination (s) & BF & $20.48 \pm 6.73$ & $0.001^{*}$ & $16.51 \pm 8.35$ & 0.48 & $14.51 \pm 2.74$ & 0.17 & $23.81 \pm 8.90$ & $0.012^{*}$ \\
& AF & $16.02 \pm 4.09$ & & $15.75 \pm 9.19$ & & $12.87 \pm 1.71$ & & $19.89 \pm 9.15$ & \\
Agility (s) & BF & $26.30 \pm 13.73$ & 0.33 & $31.34 \pm 11.31$ & 0.74 & $25.08 \pm 4.59$ & 0.94 & $33.81 \pm 17.77$ & 0.43 \\
& AF & $32.03 \pm 13.10$ & & $29.45 \pm 10.62$ & & $24.67 \pm 3.40$ & & $38.84 \pm 13.87$ & \\
Strength (rep) & BF & $18.28 \pm 6.62$ & $0.004^{*}$ & $21.28 \pm 6.65$ & $0.01 *$ & $23.00 \pm 5.26$ & $0.01 *$ & $15.50 \pm 5.89$ & $0.005^{*}$ \\
& AF & $22.42 \pm 5.76$ & & $24.57 \pm 5.06$ & & $26.25 \pm 4.49$ & & $19.83 \pm 4.16$ & \\
Aerobic Resistance & BF & $10.11 \pm 3.11$ & 0.89 & $10.03 \pm 1.80$ & 0.87 & $8.76 \pm 0.91$ & 0.72 & $11.83 \pm 2.81$ & 0.47 \\
(min) & AF & $10.16 \pm 3.06$ & & $10.10 \pm 2.97$ & & $8.63 \pm 0.71$ & & $12.13 \pm 3.56$ & \\
$* p<0.05$ & & & & & & & & &
\end{tabular}

of functional capacity in patients with Parkinson's disease and assist in maintaining other components of functional capacity and clinical characteristics. Studies have shown that physical activity is beneficial for aerobic endurance and muscle endurance in patients with PD, specifically with high-intensity interventions (Dibble, Hale, Marcus, Gerber, \& LaStayo, 2009). However, to date, no study has analyzed the effects of long-term (6 months) multimodal exercise training on the components of functional capacity in this population. In healthy elderly individuals, this type of exercise improves muscle strength and functional capacity (Deschenes \& Kraemer, 2002). Thus, our results generally suggest that long-term multimodal exercise programs can produce benefits in the functional capacity of patients with PD as well as the elderly, improving their quality of life and ability to perform daily activities. An efficient multimodal exercise program appears to improve the integration and processing of somatosensory information, encouraging greater structural adaptation and activities that increase dopamine levels, thereby promoting learning/relearning (Fox et al., 2006). Finally, strength appears to be the functional capacity most sensitive to an exercise program. This ability improved independent of gender and disease severity. Reduced muscle strength has been identified as a motor disability in PD, contributing to reduced mobility, increased number of falls and bradykinesia (Paul, Canning, Sherrington, \& Fung, 2012). Berardelli, Rothwell, Thompson, and Hallet (2001) have suggested that improved muscle strength could improve bradykinesia due to greater integration of sensory information by the basal ganglia, resulting in improved motor planning and greater muscle recruitment to initiate movement.

Multimodal exercise programs appear to improve the components of functional capacity according to disease severity. The exercise rehabilitation literature for PD has had difficulty reaching a consensus on which type of exercise is most beneficial due to the wide variety of outcome measures, disease severity, exercise types, and subjects studied (Deane et al., 2002; de Goede, Keus, Kwakkel, \& Wagenaar, 2001; Sage \& Almeida, 2009). Our results indicate that strength improves independent of disease severity. However, for the other components of functional capacity, patients in the early stage of disease maintained functional capacity, while patients in the most advanced stages showed improvements in balance and coordination. These findings can be explained by the better clinical status of patients in the unilateral disease group whose motor symptoms were not as severe (Hoehn \& Yahr, 1967). This group did not need as much improvement in motor symptoms as the bilateral disease group. In addition, the multimodal exercise program appears to improve the supply of dopamine and the functioning of the basal ganglia, which are worse in the bilateral group due to long-term use of drugs that decrease in effectiveness over time (Katzenschlager \& Lees, 2002). Movements of appendicular muscles and posture improved for the bilateral group, reflecting improved balance, coordination and functionality (UPDRSfunctional). Finally, despite the greater benefits for the bilateral group, exercise should be introduced at an early stage of the disease to slow its progression, improve corticospinal motor excitability and neuroplasticity (Fox et al., 2006; Fisher et al., 2008), and help attenuating the effects of medication (Baatile, Langbein, Weaver, Maloney, \& Jost, 2000).

Gender appears to be an important factor in the beneficial effects of an exercise program for components of functional capacity. Men showed improvements in strength and coordination, while women only improved in strength. The influence of gender on the clinical features of the disease after its onset, with females exhibiting more impairment in postural stability, depression, and reduced ability to conduct daily activities (Rojo et al., 2003; Uitti, Baba, Wszolek, \& Putzke, 2005), may have influenced the effects of the exercise program. In addition, differential hormonal effects, specifically related to estrogen, can cause gender differences in disease progression, such as milder motor deterioration for women than for men (Haaxma et al., 2007), and most likely affect functional capacity. Furthermore, everyday activities (environmental influence) are different for men and women, which may have an important effect on the results of the study (Strycker, Duncan, Chaumeton, Duncan, \& Toobert, 2007; Johannsen et al. 2008). Women perform more 
activities involving coordination during the day, while men have more experience in gross or rudimentary motor activity. In part, these differences in daily activities explain the improvement in coordination for men. Therefore, some caution is necessary with similar interventions for different genders because the specific needs of each gender may not be the same.

Even with consistent and relevant results, this study has certain limitations. There was no improvement in aerobic capacity. Cardiorespiratory capacity is a component of physical fitness related to health that declines with increasing age; low cardiorespiratory capacity may trigger degenerative diseases, such as hypertension, diabetes, or heart problems (Erikssen, 2001; Sui et al., 2007; Kodama et al., 2009). Therefore, good cardiovascular capacity improves physical fitness, reduces functional decline and contributes to an independent and healthy lifestyle (American College of Sports Medicine, 2000; Erikssen, 2001). Another limitation is the lack of a control group to compare the effects of this training on healthy elderly individuals. However, the study findings are not compromised because the main comparisons made in the study were based on disease severity and gender. Nevertheless, we suggest the inclusion of a control group matched for gender and disease severity in future studies. Finally, the results for severity of disease must be carefully analyzed due to differences between groups in the components of functional capacity before the multimodal exercise program.

In conclusion, a multimodal exercise program is efficient in improving coordination and strength of patients with PD and maintaining other components of functional capacities and clinical characteristics. Gender might be an issue when planning an exercise program. Individuals in the bilateral disease group appear to benefit more from the multimodal exercise program.

\section{References}

American College of Sports Medicine. (2000). ACSM's Guidelines for exercise testing and prescription. Philadelphia: Lippincott Williams \& Wilkins.

Baatile, J., Langbein, W. E., Weaver, F., Maloney, C., \& Jost, M. B. (2000). Effect of exercise on perceived quality of life of individuals with Parkinson's disease. Journal of Rehabilitation Research and Development, 37, 529-534.

Baldereschi, M., Di Carlo, A., Rocca, W. A., Vanni, P., Maggi, S., Perissinotto, E., ... Inzitari, D. (2000). Parkinson's disease and parkinsonism in a longitudinal study: two-fold higher incidence in men. ILSA Working Group. Italian Longitudinal Study on Aging. Neurology, 55, 1358-1363.

Barbieri, F. A., Rinaldi, N. M., Santos, P. C., Lirani-Silva, E., Vitório, R., Teixeira-Arroyo, C., ... PROPARKI Group. (2012). Functional capacity of Brazilian patients with Parkinson's disease (PD): relationship between clinical characteristics and disease severity. Archives of Gerontology and Geriatrics, 54, e83-88.

Barbosa, M. T., Caramelli, P., Maia, D. P., Cunningham, M. C. Q., Guerra, H. L., Lima-Costa, M. F., \& Cardoso, F. (2006). Parkinsonism and Parkinson's disease in the elderly: a community-based survey in Brazil (the Bambuí Study). Movement Disorders, 21, 800-808.

Berardelli, A., Rothwell, J., Thompson, J. P., \& Hallet, M. (2001). Pathophysiology of bradykinesia in Parkinson's disease. Brain, 124, 2131-2146.

Cantuti-Castelvetri, I., Keller-McGandy, C., Bouzou, B., Asteris, G.,
Clark, T. W., Frosch, M. P., \& Standaert, D. G. (2007). Effects of gender on nigral gene expression and parkinson disease. Neurobiology of Disease, 26, 606-614.

Cyarto, E. V., Brown, W. J., Marshall, A. L., \& Trost, S. G. (2008). Comparison of the effects of a home-based and group-based resistance training program on functional ability in older adults. American Journal of Health Promotion, 23, 13-17.

de Goede, C. J., Keus, S. H., Kwakkel, G., \& Wagenaar, R. C. (2001). The effects of physical therapy in Parkinson's disease: a research synthesis. Archives of Physical Medicine and Rehabilitation, 82, 509-515.

Deane, K. H., Ellis-Hill, C., Jones, D., Whurr, R., Ben-Shlomo, Y., Playford, E. D., \& Clarke, C. E. (2002). Systematic review of paramedical therapies for Parkinson's disease. Movement Disorders, 17, 984-991.

Deschenes, M. R., \& Kraemer, W. J. (2002). Performance and physiologic adaptations to resistance training. American Journal of Physical Medicine \& Rehabilitation, 81, S3-16.

Dibble, L. E., Hale, T. F., Marcus, R. K., Gerber, J. P., \& LaStayo, P. C. (2009). High intensity eccentric resistance training decreases bradykinesia and improves quality of life in persons with Parkinson's disease: A preliminary study. Parkinsonism and Related Disorders, 15, 752-757.

Erikssen, G. (2001). Physical fitness and changes in mortality: the survival of the fittest. Sports Medicine, 31, 571-576.

Fisher, B. E., Wu, A. D., Salem, G. J., Song, J., Lin, C. H, Yip, J., ... Petzinger, G. (2008). The effect of exercise training in improving motor performance and corticomotor excitability in people with early Parkinson's disease. Archives of Physical Medicine and Rehabilitation, 89, 1221-1229.

Fox, C. M., Ramig, L. O., Ciucci, M. R., Sapir, S., McFarland, D. H., $\&$ Farley, B. G. (2006). The science and practice of LSVT/LOUD: neural plasticity principled approach to treating individuals with Parkinson's disease and other neurological disorders. Seminars in Speech and Language, 27, 283-299.

Gobbi, L. T., Oliveira-Ferreira, M. D., Caetano, M. J., Lirani-Silva, E., Barbieri, F. A., Stella, F., \& Gobbi, S. (2009). Exercise programs improve mobility and balance in people with Parkinson's disease. Parkinsonism \& Related Disorders, 15, S49-S52.

Goodwin, V. A., Richards, S. H., Taylor, R. S., Taylor, A. H., \& Campbell, J. L. (2008). The effectiveness of exercise interventions for people with Parkinson's disease: a systematic review and meta-analysis. Movement Disorders, 23, 631-640.

Haaxma, C. A., Bloem, B. R., Borm, G. F., Oyen, W. J., Leenders, K. L., Eshuis, S., ... Horstink, M. W. (2007). Gender differences in Parkinson's disease. Journal of Neurology, Neurosurgery, and Psychiatry, 78, 819-824.

Hackney, M. E., \& Earhart, G. M. (2010). Effects of dance on balance and gait in severe Parkinson disease: a case study. Disability and Rehabilitation, 32, 679-684.

Hoehn, M. M., \& Yahr, M. D. (1967). Parkinsonism: Onset, progression and mortality. Neurology, 17, 427-442.

Jankovic, J., \& Stacy, M. (2007). Medical management of levodopa-associated motor complications in patients with Parkinson's disease. CNS Drugs, 21, 677-692.

Johannsen, D. L., DeLany, J. P., Frisard, M. I., Welsch, M. A., Rowley, C. K., Fang, X., ... Louisiana Healthy Aging Study. (2008). Physical activity in aging: comparison among young, aged, and nonagenarian individuals. Journal of Applied Physiology, 105, 495-501.

Katzenschlager, R., \& Lees, A. J. (2002). Treatment of Parkinson's disease: levodopa as the first choice. Journal of Neurology, 249, 19-24.

Kodama, S., Saito, K., Tanaka, S., Maki, M., Yachi, Y., Asumi, M., ... Sone, H. (2009). Cardiorespiratory fitness as a quantitative predictor of all-cause mortality and cardiovascular events in healthy 
men and women: a meta-analysis. Journal of the American Medical Association, 301, 2024-2035.

Morris, M. E., Huxham, F., McGinley, J., Dodd, K., \& Iansek, R. (2001). The biomechanics and motor control of gait in Parkinson disease. Clinical Biomechanics, 16, 459-470.

Osness, W. H., Adrian, M., Clark, B., Hoeger, W., Raab, D., \& Wiswell, R. (1990). Functional Fitness Assessment for Adults over 60 Years: A Field Based Assessment. Reston: The American Alliance for Health, Physical Education, Recreation and Dance.

Paul, S. S., Canning, C. G., Sherrington, C., \& Fung, V. S. C. (2012). Reduced muscle strength is the major determinant of reduced leg muscle power in Parkinson's disease. Parkinsonism and Related Disorders, 18, 974-977.

Pavon, J. M., Whitson, H. E., \& Okun, M. S. (2010). Parkinson's disease in women: a call for improved clinical studies and for comparative effectiveness research. Maturitas, 65, 352-358.

Rantanen, T., Guralnik, J. M., Foley, D., Masaki, K., Leveille, S., Curb, J. D., \& White, L. (1999). Midlife hand grip strength as a predictor of old age disability. The Journal of the American Medical Association, 281, 558-560.

Rojo, A., Aguilar, M., Garolera, M. T., Cubo, E., Navas, I., \& Quintana, S. (2003). Depression in Parkinson's disease: clinical correlates and outcome. Parkinsonism and Related Disorders, 10, 23-28.

Rubinstein, T. C., Giladi, N., \& Hausdorff, J. M. (2002). The power of cueing to circumvent dopamine deficits: a review of physical therapy treatment of gait disturbances in Parkinson's disease. Movement Disorders, 17, 1148-1160.

Sage, M. D., \& Almeida, Q. J. (2009). Symptom and gait changes after sensory attention focused exercise vs aerobic training in Parkinson's disease. Movement Disorders, 24, 1132-1138.

Sage, M. D., \& Almeida, Q. J. (2010). A positive influence of vision on motor symptoms during sensory attention focused exercise for Parkinson's disease. Movement Disorders, 25, 64-69.

Scalzo, P. L., Nova, I. C., Perracini, M. R., Sacramento, D. R., Cardoso, F., Ferraz, H. B., \& Teixeira, A. L. (2009). Validation of the Brazilian version of the Berg balance scale for patients with Parkinson's disease. Arquivos de Neuro-Psiquiatria, 67, 831-835.

Scott, B., Borgman, A., Engler, H., Johnels, B., \& Aquilonius, S. M. (2000). Gender differences in Parkinson's disease symptom profile. Acta Neurologica Scandinavica, 102, 37-43.

Shulman, L. M., \& Bhat, V. (2006). Gender disparities in Parkinson's disease. Expert Review of Neurotherapeutics, 6, 407-416.

Strycker, L. A., Duncan, S. C., Chaumeton, N. R., Duncan, T. E., \& Toobert, D. J. (2007). Reliability of pedometer data in samples of youth and older women. International Journal of Behavioral Nutrition and Physical Activity, 17, 4:4.

Sui, X., LaMonte, M. J., Laditka, J. N., Hardin, J. W., Chase, N., Hooker, S. P., \& Blair, S. N. (2007). Cardiorespiratory fitness and adiposity as mortality predictors in older adults. Journal of the American Medical Association, 298, 2507-2516.

Uitti, R. J., Baba, Y., Wszolek, Z. K., \& Putzke, D. J. (2005). Defining the Parkinson's disease phenotype: initial symptoms and baseline characteristics in a clinical cohort. Parkinsonism and Related Disorders, 11, 139-145.

Van Den Eeden, S. K., Tanner, C. M., Bernstein, A. L., Fross, R. D., Leimpeter, A., Bloch, D. A., \& Nelson, L. M. (2003). Incidence of Parkinson's disease: variation by age, gender, and race/ethnicity. American Journal of Epidemiology, 157, 1015-1022.

\author{
Authors' note \\ Diego Orcioli-Silva, Lucas Simieli, Fabio Augusto Barbieri, Rodrigo \\ Vitório, and Lilian Teresa Bucken Gobbi are with the Posture and Gait \\ Studies Laboratory (LEPLO), Department of Physical Education, São \\ Paulo State University, Rio Claro, São Paulo, Brazil. \\ Natália Madalena Rinaldi is with the Biomechanics and Motor Con- \\ trol Laboratory, School of Physical Education and Sport of Ribeirão \\ Preto, University of São Paulo, Ribeirão Preto, São Paulo, Brazil and \\ the Ribeirão Preto Medical School, University of São Paulo, Ribeirão \\ Preto, São Paulo, Brazil.

\section{Corresponding author:} \\ Diego Orcioli-Silva \\ Universidade Estadual Paulista \\ Laboratório de Estudos da Postura e da Locomoção - Departamento \\ de Educação Física \\ Avenida 24-A, 1515, Bela Vista, 13506-900, Rio Claro, São Paulo, \\ Brasil \\ Fone: + $55193526-4365$ \\ Fax: + $55193534-6436$ \\ e-mail: diego_orcioli@hotmail.com
}

\section{Acknowledgments:}

The authors thank each movement disorder specialist in the PROPARKI Group. The authors thank CNPq, CAPES, FAPESP and PROEX for financial support.

Manuscript received on March 29, 2013

Manuscript accepted on December 4, 2013

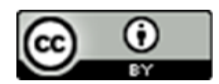

